\title{
ANA MARIA EUGÊNIO DA SILVA: UMA QUILOMBOLA QUE VENCEU O CÂNCER ESCREVENDO E DANÇANDO COM SÃO GONÇALO
}

\section{- FERNANDA IELPO DA CUNHA}

http://orcid.org/0000-0002-4429-5555

Universidade da Integração Internacional da Lusofonia Afro-brasileira

\section{ANA MARIA EUGÊNIO DA SILVA}

http://orcid.org/0000-0002-6121-7882

Universidade da Integração Internacional da Lusofonia Afro-brasileira

\section{JOSÉ GERARDO VASCONCELOS}

http://orcid.org/0000-0003-0559-2642

Universidade Federal do Ceará

RESUMO O processo da descoberta do câncer de mama, os impactos, as angústias, o medo e ainda a discriminação foram os assuntos discorridos nesta pesquisa. A autobiografia de uma mulher negra quilombola revela os caminhos percorridos para o tratamento realizado através do Sistema Único de Saúde e a importância da sua autobiografia e espiritualidade na superação de sua enfermidade. 0 estudo chama a atenção para a importância do recorte étnico-racial frente às políticas públicas de saúde destinadas à população negra, especialmente à mulher quilombola, cujas singularidades e particularidades não são compreendidas nem respeitadas por grande parte dos profissionais de saúde, o que repercute na fragmentação de ações pontuais se comparadas àquelas destinadas a mulheres brancas. A metodologia é exploratório-descritiva, com revisão de literatura e análise autobiográfica da autora em questão. Os resultados revelam o quanto foram importantes a autobiografia e a dimensão da espiritualidade para a autora, ressignificando a sua vida positivamente e fazendothe protagonista de sua história.

Palavras-chave: Autobiografia. Câncer de mama. Dança de São Gonçalo. Espiritualidade. 


\section{ABSTRACT ANA MARIA EUGÊNIO DA SILVA: A QUILOMBOLA THAT OVERCOMED CANCER WRITING AND DANCING WITH SÃO GONÇALO}

The process of breast cancer discovery, impacts, anguishes, fear and even discrimination were the topics discussed in this research. The autobiography of a quilombola black woman reveals the paths taken for treatment through the Unified Health System and the importance of her autobiography and spirituality in overcoming her illness. The study draws attention to the importance of the ethno-racial approach to public health policies aimed at the black population, especially the quilombola women, whose singularities and particularities are not understood or respected by most health professionals, which impacts on fragmentation of specific actions compared to those aimed at white women. The methodology is exploratory and descriptive, with literature review and autobiographical analysis of the author in question. The results reveal how important were the autobiography and the dimension of spirituality for the author, positively resignifying her life and making her protagonist of her history.

Keywords: Autobiography. Breast cancer. São Gonçalo Dance. Spirituality.

\section{RESUMEN}

\section{ANA MARIA EUGÊNIO DA SILVA: UNA QUILOMBOLA QUE VENCIÓ AL CÁNCER ESCRIBIENDO Y BAILANDO CON SAN GONZALO}

Este estudio trata de temas relacionados al proceso de descubrimiento del cáncer de mama, los impactos de esa enfermedad, las angustias, el miedo y la discriminación hacia ella. La autobiografía de una mujer negra quilombola revela los caminos recorridos hacia el tratamiento realizado a través del Sistema Único de Salud y la relevancia de su autobiografía y espiritualidad en la superación de su enfermedad. El estudio pone de relieve la importancia del ámbito étnico-racial ante las políticas públicas de salud destinadas a la población negra, sobre todo la mujer quilombola, cuyas singularidades e idiosincrasias no son comprendidas ni respetadas por muchos de los profesionales de salud, lo que resulta en la fragmentación de acciones puntuales si se comparan con las acciones destinadas a las mujeres blancas. La metodología es exploratorio-descriptiva, con revisión de literatura y análisis autobiográfico de la autora en cuestión. Los resultados indican la importancia que tuvieron la autobiografia 
y la dimensión de la espiritualidad para la autora, resignificando su vida positivamente y convirtiéndola en protagonista de su historia.

Palabras clave: Autobiografía. Cáncer de mama. Baile de São Gonzalo. Espiritualidad.

\section{Introdução}

Ela se chama Ana Eugênio, belíssimo nome, carregado de luta e resistência. Ana, "aquela que é benéfica, que tem compaixão"; Eugênia, "aquela que é bem nascida ou aquela que tem origem nobre", conforme consta no site Significado do Nome. Assim, a personagem aqui tratada carrega no nome a resistência, cujas raízes possuem ancestralidade africana de uma mulher forte, disposta a resistir e a lutar até o fim. Essas características se destacam como elementos-chave da autobiografia e das narrativas escritas por essa mulher, que chorou ao saber do seu diagnóstico de câncer de mama, mas renasceu depois das lágrimas, encontrando uma forma de superação, resiliência e fé na escrita de seus relatos autobiográficos e na dança de São Gonçalo.

[...] fico a pensar nos sujeitos acometidos pelo câncer que não sabem ler, escrever, pois não tiveram oportunidade de estudar, assim como eu tive. Penso que estes devem sofrer ainda mais com o impacto da doença. Por isso, a escrita foi uma das maneiras de desabafo e também de enfrentamento e superação do câncer de mama. (SILVA, 2018, p. 17)

A autobiografia, nesse sentido, é utilizada como um mecanismo de autodefesa emocional que possibilita ir ao encontro das memórias e reminiscências mais profundas de sua existência, lugar secreto e introspectivo do seu refúgio interior, descobrindo a si mesma, seus medos, traumas, dores, alegrias e força motriz, força esta capaz de escrever, de registrar fragmentos de sua história, de sua árvore genealógica e dos ensinamentos de seus ancestrais.
A lembrança remete o sujeito a observar-se numa dimensão genealógica, como um processo de recuperação do eu, e a memória narrativa, como virada significante, marca um olhar sobre si em diferentes tempos e espaços, os quais se articulam com as lembranças e as possibilidades de narrar experiências. (SOUZA, 2007, p. 141)

O método autobiográfico utilizado por Ana Eugênio permite, portanto, fazer uma análise de sua história de vida, das vivências e experiências reveladas pela escrita, suas poesias, a dança de São Gonçalo, sua cultura, revelandose como um ser não isolado, mas que está no mundo, que pensa, emociona-se, luta, tem desejos e busca transformar a si e a seu entorno, o mundo.

O fazer biográfico é importante porque com ele percebemos a trajetória de mulheres e homens como sujeitos da história, vemos como os documentos representam os indivíduos e como esses são representados por suas escrituras e pelas escritas dos outros, o biografado com um todo, do indivíduo ao coletivo (ALMEIDA, 2018, p. 49)

Cabe ressaltar que o ato de narrar e descrever sua própria autobiografia deixa para a ciência e a pesquisa os caminhos de aproximação com a realidade vivida pelas mulheres quilombolas, com fundamento em: crenças, valores, relação com a terra e o território, dimensão do sobrenatural revelada pelos ensinamentos dos seus ancestrais, tradição da dança de São Gonçalo e sua relação com a espiritualidade, na busca da cura e resgate de sua saúde, ampliando o debate do câncer de mama a partir das especificidades de uma mu- 
Iher de origem quilombola ainda pouco exploradas e debatidas nos espaços acadêmicos e da pesquisa.

Este método abre caminhos para contestar a cientificidade positivista que tanto discriminou os registros históricos das populações tradicionais. Nesse modelo, tais sujeitos sociais tiveram sua oralidade silenciada, foram meros espectadores de suas histórias e vivências, resultando na superficialidade e não originalidade de suas verdadeiras histórias. Daí a importância de colocar as populações étnicas como protagonistas de sua própria história, fazendo com que transponham para o mundo a essência de suas memórias e narrativas autobiográficas, o seu potencial criativo.

É fato notório na história das ciências humanas a influência exercida pelos métodos experimentais desenvolvidos no âmbito das ciências físicas e biológicas, sobre as formas com que cada uma se conduziu para investigar os fenômenos sociais que thes dizem respeito. Entretanto, o que foi a princípio um verdadeiro fascínio - pois servir-se de tais métodos era a condição para se ter o reconhecimento como disciplina científica - veio a se tornar com o tempo uma verdadeira tirania [...]. Não se trata aqui de reconstituir essa história, mas de lembrar que este é um dos principais pontos que dão origem às insatisfações que vão surgindo no interior de cada uma dessas disciplinas e ensejam um movimento de rupturas e mudanças que se iniciou nas primeiras décadas do século passado e não cessou de se desenvolver até os dias de hoje. Tais mudanças dizem respeito não somente à busca de novos métodos de investigação, mas, sobretudo, a um modo novo de conceber a própria ciência. Ou seja, ao abrir mão dos métodos experimentais e seus correlatos, que traduziam a ambição de se constituir em cada campo uma ciência racional e objetiva, capaz de dar conta da tarefa de descobrir as regularidades que ocorrem na natureza e as leis que regem tais fenômenos, estava-se na verdade abdicando de um conceito de ciência em favor de outro. (BUENO, 2002, p. 13-14)
A autora supracitada afirma ainda a relevância de irmos ao encontro de novos métodos científicos, capazes de extrair a subjetividade de sujeitos sociais que durante tanto tempo foram esquecidos e até relegados nas ciências. Enfatiza que é preciso compreendermos os aspectos subjetivos dos sujeitos sociais, a oralidade, situando-os também como sujeitos de suas histórias. "[...] A subjetividade passa a se constituir, assim, na ideia nuclear, vale dizer, no próprio conceito articulador das novas formulações teóricas e das propostas que realimentam a área a partir dessa viragem" (BUENO, 2002, p. 13).

Assim, é preciso que os sujeitos sociais narrem suas histórias de dentro de suas entranhas, colocando-se como protagonistas de suas reminiscências, rompendo com a objetividade imposta pelo modelo de neutralidade e objetividade, que não representa as comunidades tradicionais quilombolas, por exemplo. “[...] da contestação do positivismo que emergem as possibilidades de um novo paradigma compreensivo. Temos que perceber a alteração do real produzida pelas ações concretas dos atores sociais [...]" (SOUZA, 2007, p. 140).

Dito isso, Ana Eugênio, com plena consciência e lucidez, mostra a relevância da autobiografia, uma maneira que encontrou de se afirmar no mundo como mulher negra quilombola, colocando-se como protagonista de sua própria história, assim como trazendo para o debate acadêmico caminhos para se aproximar da realidade e historicidade dessa população, da qual pouco se sabe ou da qual o que se sabe é sob a percepção do homem branco ocidental, que negou a cultura dos povos africanos e suas diásporas no mundo, considerando-os selvagens, primitivos e não civilizados e/ou situando-os como representantes de uma cultura pagã e de "menor valor".

Logo, esse olhar hoje não representa em sua legitimidade a verdadeira história e cul- 
tura africana e de seus afrodescendentes (DOMINGOS, 2017). Aqui é a autora narrando e se revelando para o mundo através da escrita, colocando-se como sujeito de sua própria história, como protagonista de seu enredo, de sua vida, da memória latente mergulhada na profundidade da imensidão da sua essência feminina, no interior e esconderijo de sua alma, trazendo para a pesquisa e a ciência uma autobiografia a partir de suas entranhas, da sua gênese, como afirma:

Os relatos aqui trabalhados foram elaborados a partir de minha vivência. Neste momento, assumo-me enquanto sujeito de minha própria história, trazendo nesta escrita as dimensões científica, ético-política e poética. Compartilhando, assim, minhas vivências tendo ciência de que a escrita tem sido uma das formas de enfrentamento e superação do câncer de mama. (SILVA, 2018, p. 16)

Assim, este artigo se preocupou especialmente em dar visibilidade à autobiografia de Ana Eugênio, por situar questões relevantes para o cunho acadêmico, cuja relevância da pesquisa autobiográfica traz um debate capaz de revelar, a partir de sua própria escrita, sua história de vida, sem a presença de um pesquisador e de técnicas que intimidassem ou trouxessem constrangimento. A metodologia adotada segue a abordagem qualitativa, visto que se aproxima mais das crenças, valores, costumes e vivências dos sujeitos sociais, considerando a sua essência humana, os aspectos biopsicossociais, que podem ser apreendidos em seu cotidiano, nas vivências e na própria explicação do senso comum (MINAYO, 2004).

A importância deste estudo biográfico revela-se na metodologia exploratório-descritiva com a revisão da literatura e análise bibliográfica com recorte da autobiografia de Ana Eugênio e de sua obra intitulada Enfrentamento e superação do câncer de mama: narrativa autobiográfica de uma mulher negra quilombola, apresentada à Universidade Estadual do Ceará (UECE) para a obtenção do título de graduação em Serviço Social no ano de 2018.

Nesse sentido, a fim de ampliar as discussões acima suscitadas, elegemos as categorias: autobiografia e câncer de mama, atreladas à dança de São Gonçalo e à espiritualidade, cuja compreensão é de fundamental importância para o entendimento da trajetória de vida da autora, dos meios encontrados por ela para amenizar o seu sofrimento e dos processos de cura com base nos ensinamentos de seus ancestrais somados aos da medicina convencional.

\section{A autobiografia e o câncer: um olhar para as especificidades e singularidades das mulheres quilombolas}

Descobrir um diagnóstico de câncer não é algo fácil, até porque a maioria das pessoas já tem em mente sua própria sentença de morte, algo semelhante, segundo a autora: “[...] [a]o cantar do galo fora de hora e [a]o canto melancólico da acauã, que anuncia que algo sinistro vai ocorrer [...]" (SILVA, 2018, p. 17). Esse sentimento foi, sem sombra de dúvidas, o primeiro vivenciado pela autora ao receber a notícia da confirmação da tão temida doença, encontrando na sua autobiografia uma maneira de narrar sua experiência com o câncer de mama, como uma forma de desabafo, um refúgio no seu mundo interior mais profundo, um alivio para sua dor.

Toda essa luta que vivenciei e que ainda vivencio faz-me refletir que, ao longo dos meus 45 anos, sempre tive que lutar, nada foi fácil, sobretudo quando soube do diagnóstico. Ao relatar, vejo o quanto é relevante o ato de ler e escrever, sobretudo no momento da descoberta da doença, em que a fala, a voz falhava e o choro tomou conta de mim, mas, ao mesmo 
tempo, as lágrimas lavavam todos os medos, as incertezas que havia dentro de mim. (SILVA, 2018, p. 17)

A autobiografia utilizada pela autora instiga não somente o debate sobre o câncer, que tem ceifado milhares de mulheres, mas a ampliação de um olhar com o recorte étnico-racial, dado que as mulheres negras, as afrodescendentes e as quilombolas têm especificidades que as deixam mais vulneráveis a alguns tipos de cânceres mais agressivos, como o triplo negativo ${ }^{1}$, somadas às dificuldades ora enfrentadas no Sistema único de Saúde (SUS) e na própria atenção primária, que se organiza por meio das equipes de saúde de família, o que poderá agravar e acelerar o processo de evolução da doença.

De acordo com o INCA (Instituto Nacional de Câncer), o câncer de mama é o tipo de câncer que mais acomete as mulheres em todo o mundo. 'O câncer é o nome dado a um conjunto de mais de 100 doenças que têm em comum o crescimento desordenado (maligno) de células que invadem os tecidos e órgãos, podendo espalhar-se (metástase) para outras regiões do corpo'. O câncer de mama acomete uma ou as duas mamas e, por vezes, as axilas, manifestando-se no início como um nódulo. Esse tipo de câncer é mais comum em mulheres acima de 35 anos e, embora possua um bom prognóstico quando identificado no início, é considerado um problema de saúde pública. (INCA, 2014 apud ROCHA; ALMEIDA; RIBEIRO, 2013, p. 7)

Considerando a realidade acima exposta, o que se percebe nessa política e serviços primários é toda uma fragilidade de ações sistematizadas, principalmente para as mulheres que residem no campo, muitas vezes distantes dos espaços de saúde e com pouco acesso às informações se comparadas às mulheres brancas da zona urbana, que têm um atendimento

1 "O câncer chamado triplo negativo é duas vezes mais comum em mulheres negras. É um tipo mais agressivo, de dificil identificação, que tem mais facilidade de se espalhar pelo corpo" (CORREIO NAGÔ, 201-, p. 1). mais amplo e próximo delas, tendo as mulheres do campo, especificamente as quilombolas, que se adequar ao agendamento do Programa de Saúde Local (Programa Saúde da Família - PSF), mostrando que, embora a Política Nacional de Saúde Integral da População Negra (PNSIPN) assegure a ampliação do acesso ao atendimento básico, na prática deixa uma grande lacuna entre o que preconiza a lei e sua efetivação. Tudo isso afeta nitidamente a realidade das comunidades quilombolas, como enfatiza Silva (2018, p. 41):

No município de Quixadá, existem diversas equipes de saúde da família para atender à população urbana e rural. No distrito de Dom Maurício, onde moro, tem um posto de saúde que atende à população do Quilombo e adjacências. Consta no calendário da equipe de saúde da família o atendimento dentro do Quilombo Veiga uma vez por mês, mas, quando se aproximava o dia de atendimento, ocorriam imprevistos e era remarcado para o mês seguinte. Para que tivesse agenda de atendimento, houve muitas reivindicações por meio de abaixo-assinado, denúncias e mobilizações por parte das famílias quilombolas. Para conseguir uma consulta no posto de saúde que está há $3 \mathrm{~km}$ do Sítio Veiga, era preciso sair de casa à noite com o intuito de assegurar uma ficha, pois eram somente 16 fichas distribuídas para todos que buscavam atendimento. Diversas vezes conseguiam a ficha, mas a equipe médica não comparecia. Os motivos eram muitos e sempre os mesmos: ausência de gasolina, pneu furado ou careca, a estrada estava ruim, dentre outros.

É notório, portanto, que equidade foge muito da realidade cotidiana dessas mulheres, cujas longas filas de espera, atendimentos pontuais e ações fragmentadas ferem nitidamente o direito delas de transitar em pé de igualdade com os demais sujeitos sociais, além de tirarem a sua autonomia sobre a escolha de suas demandas, da garantia de um entendimento particularizado de suas especificidades e singularidades, do conhecimento de suas realidades locais e da dimensão do 
território, das condições socioeconômicas e habitacionais, sendo, na maioria das vezes, invisibilizadas e/ou ignoradas pelas equipes de saúde.

[...] 0 princípio da igualdade sempre foi descrito nas Constituições brasileiras desde a época imperial como a ação de se tratar de forma igual os iguais e de forma desuniforme os desiguais, no sentido de alcançar a equidade. Cabe, então, refletir até que ponto a implantação de políticas e programas do SUS pode ser observada como gesto qualificado para a promoção de ações e serviços que estabeleçam o direito de as comunidades escolherem os atendimentos de suas prioridades frente às necessidades, tornando-os protagonistas. (VIEIRA; MONTEIRO, 2013, p. 611)

Ampliando suas críticas sobre os aspectos anteriormente mencionados, Ana Eugênio avalia a própria incoerência que envolve as campanhas pontuais e fragmentadas, como o Outubro Rosa ${ }^{2}$. Tais ações, apesar de chamarem a atenção para a importância da realização da prevenção do câncer e de exames específicos, a exemplo da mamografia e da ultrassonografia, na prática esses serviços tornam-se morosos, sendo, mais uma vez, preciso aguardar nas filas de espera a marcação, o que acarreta supostamente em um diagnóstico tardio, podendo ocasionar, inclusive, a mortalidade dessas mulheres.

[...] os debates e informações deveriam ser pautados com mais frequência pelos profissionais da saúde, de modo que essas informações de prevenção e acesso ao tratamento de câncer atinjam toda a população do campo e cidade, respeitando suas singularidades. É comum e visto como normal que estas informações (palestras, roda de conversa) não cheguem aos povos do campo, das águas e das florestas, em particular aos remanescentes de quilombolas, visto que estes tendem a morar em espaços

2 "O Outubro Rosa é um movimento internacional que visa à conscientização sobre a importância de um diagnóstico precoce e da prevenção contra o câncer de mama" (SANTOS, 201-, p. 1). mais afastados e em péssimas condições sociais, econômicas, políticas e culturais. (SILVA, 2018, p. 39)

Assim, muitas mulheres, sem acesso a esses serviços e informações em tempo hábil pelas equipes de saúde, acabam sendo vítimas de seus tabus em torno do câncer, ficando enclausuradas em seus medos ao referir-se à doença ou lidarem com ela, criando, em seus imaginários psicológicos, ideias de que não se deve falar da enfermidade para não atrair para si "aquela doença"3, "bater três vezes na madeira"4 e "Ave-Maria três vezes" esses tabus, elas desconhecem seus próprios corpos, não recebem serviços adequados de prevenção, tratamento e diagnóstico, não sabem ou não têm familiaridade com o autoexame, não havendo também um suporte emocional e psicológico nos serviços de saúde capaz de realizar uma orientação mais humanizada, respeitando e conhecendo suas singularidades, o que poderá contribuir para colocar em risco suas próprias vidas.

[...] além do tabu, o câncer de mama continua sendo permeado de mitos. Outro fator é que mulheres negras têm mais chances de desenvolver a anomalia antes dos 40. Porém, o Ministério da Saúde recomenda que mulheres acima de 50 anos realizem mamografia a cada dois anos. No entanto, tal recomendação diverge do que a Sociedade Brasileira de Mastologia recomenda, esta afirma que o exame deve ser feito uma vez ao ano, a partir dos 40 , pois $25 \%$ dos casos de câncer ocorrem em mulheres nesta faixa etária. (MEDEIROS, 2016 apud SILVA, 2018, p. 13)

Isso faz lembrar as palavras de Machado (2015), que observa que a política de saúde é

3 Faz referência ao câncer, mas, por superstição derivada do medo da doença e das crendices populares, não menciona o verdadeiro nome da doença, como uma forma de se proteger e não ser acometido(a) por ela, etc.

4 Expressão ou ditados populares que fazem referência ao bater na madeira com espantar o azar.

5 Expressão ou ditado populares que significam pedir livramento de uma enfermidade, acidente, etc. 
um direito socialmente construído através da luta da classe trabalhadora. Segundo a pesquisadora, a política de saúde, desde a sua criação, sempre teve dificuldades de ser implementada, devido à política neoliberal, que carrega em si as marcas do conservadorismo sócio-histórico, cujo embrião foi fecundado ainda na Reforma Sanitária 6 . A doutrina neoliberal busca de todas as formas diminuir o tamanho do Estado, tornando-o máximo para os ricos e mínimo para os pobres.

Todavia, apesar de todos os problemas do SUS, não podemos negar alguns dos avanços no tratamento dos mais variados tipos de cânceres, uma vez que esse sistema possui uma estrutura avançada no tratamento dessa anomalia com relação ao tratamento disponibilizado pelo espaço privado. Entretanto, faz-se necessário avançar em uma série de outras questões, como na diminuição da fila de espera, acesso a medicações e a tratamento de forma geral, embora a Portaria n. 874/GM, de 16 de maio de 2013, garanta o atendimento integral a qualquer pessoa com suspeita ou diagnóstico confirmado de câncer.

Diante do exposto, não há como negar que as ações de atendimento do SUS ainda deixam muito a desejar, o que demarca a própria história da Reforma Sanitarista no Brasil, que traz em sua origem o retrato de um sistema social injusto e desigual do nosso país. Todavia, não podemos deixar de reconhecer que foi uma conquista da sociedade civil e da classe trabalhadora e hoje se legitima como uma política universal que atende a pobres, ricos, brancos e negros, sem distinção de classe, gênero, religião ou etnia, cabendo à União e aos estados

6 “O movimento da Reforma Sanitária nasceu no contexto da luta contra a ditadura, no início da década de 1970. A expressão foi usada para se referir ao conjunto de ideias que se tinha em relação às mudanças e transformações necessárias na área da saúde. Essas mudanças não abarcavam apenas o sistema, mas todo o setor saúde, em busca da melhoria das condições de vida da população" (PENSESUS, 201-, p. 1). a oferta de serviços, daí a importância de melhorar a oferta desses serviços, principalmente no tocante à realidade das mulheres que moram no campo, em particular as remanescentes quilombolas.

\section{Autobiografando uma carta de despedida: uma escrita sensivel e necessária, uma dor imensurável}

A relevância da escrita na vida de Ana Eugênio percorre diversos momentos de sua autobiografia ao saber do seu diagnóstico do câncer e ao escrever a carta intitulada "Carta de Despedida"7: cada parte de nós é um universo. Essa carta foi escrita nos momentos que antecederam a separação da sua mama do seu corpo, simbolizando o momento mais difícil da sua essência feminina.

Este texto foi um dos mais importantes para mim, pois foi escrito em um dos momentos mais dificeis, visto que já se aproximava a hora da retirada completa de minha mama. Foi o período que mais derramei lágrimas, mas também foi um tempo de grandes aprendizados, novas amizades e construções coletivas. Ao escrever este texto, percebi o quanto tudo que escrevemos/fazemos é uma construção coletiva e como essa construção é importante para a vida em sociedade. (SILVA, 2018, p. 54)

Os relatos escritos nesse momento percorrem um caminho sensivel, trazendo à tona todas as fases do tratamento, a descoberta, a realização de seus exames e as sessões de quimioterapia e radioterapia, mas talvez o momento mais delicado e de resiliência mais profunda foi quando ela precisou retirar sua mama. Esse momento foi um dos mais sagrados, adentrando na sua essência feminina, dada a representatividade dos seios para as mulheres e de sua associação ao prazer, à

$7 \quad$ A escrita desse texto se deu no dia 7 de setembro de 2016 , sendo concluída no dia 26 de setembro do mesmo ano. 
sensualidade, à vaidade, ao ser mãe, às dores e alegrias em torno da amamentação, dentre outros fatores.

O seio, na obra freudiana, está relacionado à amamentação e ao modelo de experiência de

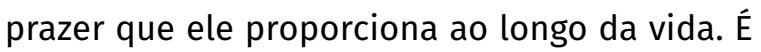
visto como símbolo da feminilidade, manifestando deslumbramento e erotismo. [...] Dessa forma, o seio é um representante das experiências do ser humano, principalmente da mulher, porque é esta quem vê o próprio seio se desenvolvendo, junto com seus afetos. (ROCHA; ALMEIDA; RIBEIRO, 2013, p. 6)

A mama nesse caso suscita a simbologia dessa representação para as mulheres, não sendo só uma forma de alimentar um outro ser, indo além da simples alimentação física, envolvendo os primeiros contatos de satisfação, prazeres e afetos entre mãe e filho (BASTOS, 1998 apud ROCHA; ALMEIDA; RIBEIRO, 2013).

Na carta, Ana Eugênio fala das diversas etapas da sua vida e do significado dos seus seios na fase da transição da infância para a adolêscencia, passando pela maternidade e chegando à retirada de sua mama. Enfatiza que ser mulher é uma construção social, pois não se nasce mulher, mas torna-se mulher (BEAUVOIR, 1967 apud SILVA, 2016, p. 56). Nas palavras de Beauvoir (1967, p. 9):

Ninguém nasce mulher: torna-se mulher. Nenhum destino biológico, psíquico, econômico define a forma que a fêmea humana assume no seio da sociedade; é o conjunto da civilização que elabora esse produto intermediário entre o macho e o castrado que qualificam de feminino. Somente a mediação de outrem pode constituir um indivíduo como um Outro. Enquanto existe para si, a criança não pode apreender-se como sexualmente diferençada. Entre meninas e meninos, o corpo é, primeiramente, a irradiação de uma subjetividade, o instrumento que efetua a compreensão do mundo: é através dos olhos, das mãos e não das partes sexuais que apreendem o universo.
Dito isso, percebe-se a maneira que Ana Eugênio vivencia essa transição de menina a mulher e sua relação com as mudanças corporais, sendo uma relação que ela considera para além do próprio sexo, construída cotidianamente com a própria história dos sujeitos sociais, como enfatizado adiante:

[...] Quando tinha em torno de onze anos, você, minha querida (mama direita), brotou de dentro de mim, percebi que estava deixando minha infância e me tornando mulher, menina mulher, mulher menina. Apesar das dores, do incômodo causado com o seu nascimento, fiquei tão feliz, e que menina não ficaria? Vestia roupas coladas, queria que visualizassem; lembro-me dos falatórios da vizinhança: - liiiiihhhh, foi picada pelo marimbondo. Ficava irritada, mas ao mesmo tempo feliz, pois a cada dia estava me tornando mulher. Como afirma Simone de Beauvoir (1974), não se nasce mulher, torna-se mulher! De fato, ninguém nasce mulher, este é um processo de construção permanente, no qual o indivíduo vai se fortalecendo cotidianamente a partir de sua construção enquanto sujeito, sujeito de sua própria história. A situação pela qual estou passando me deixará mais mulher, assim acredito e defendo que o conceito de mulher vai para além do sexo. Entretanto, passei a observar com mais nitidez o desabrochar de meus seios ao longo dos dias/meses/anos. Foi tão sublime acompanhar o crescimento de minhas mamas, porém este prazer ficou ainda mais prazeroso quando percebi a essência/dimensão do prazer para além do crescimento. Foram tantos prazeres que meus seios me proporcionaram durante o tempo em que estiveram comigo, prazer em ver meu corpo deixando de ser menina, prazer enquanto mulher e mãe. (SILVA, 2018, p. 56-57)

A fase inerente ao papel exercido de ser mãe e amamentar é apresentado por Ana Eugênio de forma bastante sofrida, repleta de dualidade, permeada por momentos de prazer e alegria, mas também de desconforto e sofrimento, principalmente quando não se tem boas condições socioeconômicas, o que compromete bastante o próprio ato de amamen- 
tar, pois, sem uma boa alimentação, fica difícil obter uma boa quantidade de leite.

[...] relatarei, grosso modo, o prazer de amamentar, de poder saciar a fome de meus filhos/ as. Compreendo e defendo o ato, a importância de amamentar, mas não é fácil e muito menos simples como dizem os/as trabalhadores/as da saúde e a população no geral. Quando ainda criança, escutava minha avó dizer: - Que a cabra dava leite pela boca. Não compreendia tal metáfora. Tempos depois compreendi que de fato, se o animal não come, também não terá condições de produzir leite. E este é apenas um dos muitos fatores que carecem de ser observados para além do senso comum. Cabe lembrar que, para a mãe produzir leite no período de lactação, se faz necessária uma série de cuidados, tais como: apoio da família, tempo, carinho e diversos outros cuidados, além da necessidade de uma alimentação saudável. Estes fatores muitas vezes não são levados em consideração e ainda há a culpabilização do indivíduo de não querer amamentar. Nos períodos em que amamentei, minha alimentação foi altamente precarizada, o reflexo era nítido na pouca produção de leite, as tonturas eram frequentes causadas pela ausência de alimentos, pois ao mesmo tempo tinha que cuidar da casa e trabalhar. Esta é a realidade da maioria das mulheres que conheço, as intensas jornadas de trabalho, o machismo e muitos outros fatores. Contudo, para amentar bem, é necessário que se tenham as condições materiais necessárias, não basta ter somente os seios, não basta ser somente mulher. Portanto, a qualidade e quantidade de leite será de acordo com as condições de quem está amamentando, isto é válido tanto para a mulher quanto para os animais no período de lactação. Embora não tendo as condições materiais necessárias, amamentei minhas crias durante alguns meses, mesmo de forma fragmentada, e isto me deu prazer. (SILVA, 2018, p. 57)

Nessa narrativa é possível observarmos que $o$ ato de amamentar não estabelece só o prazer, mas evidencia sofrimento físico e psíquico, sofrimento este que, não raro, as mulheres se recusam a revelar. Tais dores, por vezes, são sentidas emocionalmente pelo próprio ato de amamentar, agravando-se pela sobrecarga de atribuições, quando tentam conciliar a maternidade com a vida doméstica e privada, expressando angústia e sentimento de culpa pelo modelo imposto pelo padrão cultural que exige que sejam "boas mãezinhas" e "tudo suportem", fazendo com que muitas mulheres renunciem a si mesmas, a suas aspirações e desejos, ficando presas nesses papéis, o que denuncia o mal-estar da insatisfação, o medo e a culpa de não estarem realizando outras coisas que também gostariam de fazer, sobrecarregando-se de forma nenhum pouco democrática quando suas atividades desempenhadas são comparadas às de seus companheiros (CUNHA, 2000).

Muitas mulheres, nesse sentido, principalmente das classes populares, ingressam no mercado de trabalho e continuam responsáveis pela esfera doméstica, exige-se delas a proteção integral aos filhos - assim, a mãe cuidará tanto da formação (educação), quanto da satisfação das necessidades básicas, quanto da recusa ou impossibilidade do pai em realizar. (SANTIAGO, 1998 apud CUNHA, 2000, p. 58)

E, por fim, Ana Eugênio tece suas críticas à cultura machista e ao apelo da sociedade em torno de seios e corpo perfeitos. Assim, ela consegue dialogar plenamente com Beauvoir (1967), chamando a atenção para o peso que a cultura impõe sobre os corpos femininos, cuja pressão exercida coloca as mulheres em grandes armadilhas, sendo necessário desconstruir esses padrões impositivos, desconstruir essa beleza narcisista para agradar os homens e se conformar aos padrões culturais.

Os padrões culturais atravessam os corpos femininos, que não permanecem intactos aos múltiplos sentidos, desejos e injunções históricas. Dessa forma, um corpo é uma expressão singular em que a possibilidade de mudança é constante. A preocupação contemporânea com a estética corporal é exacerbada, como um culto ao corpo, no qual sua imagem varia 
conforme certas marcas identitárias: gênero, faixa etária, etnia, nacionalidade etc. 0 discurso veiculado pela mídia tem um papel especial nesse processo e na difusão de padrões de beleza. Define-se uma estética corporal através de diversas manifestações, na busca de uma imagem que ultrapasse uma certa falta. A busca ocidental de uma imagem idealizada como rica em sensualidade - um corpo feminino desejado, alvo de interesses sexualizados - leva a uma série de práticas e performances vinculadas a um individualismo, expresso na noção de autoestima. (ROCHA; ALMEIDA; RIBEIRO, 2013, p. 6-7)

Dito isso, Ana Eugênio demonstra sua indignidade com esse padrão machista, mas não desiste de lutar contra esse sistema opressor, colocando-se como uma mulher livre, protagonista de sua própria história, cuja existência jamais fará anular-se como mulher.

[...] O que mais dói é viver em uma sociedade machista, onde é criado um padrão de beleza (magra, alta, seios firmes, pele branca e cabelo liso) para nós, mulheres. Mas lutarei para continuar caminhando ainda que seja a passos lentos, mas estes serão fincados no chão e por onde eu trilhar lutarei contra estes estereótipos que nos oprime, que nos mata. (SILVA, 2018, p. 58)

As palavras da autora deixam nítido que o privilégio por certas partes do corpo feminino como expressão dessa feminilidade e sua valorização para a autoimagem poderão redundar em um sofrimento profundo quando da possibilidade dessa perda ou mutilação, sendo o câncer e a retirada da mama expressões, dentre outras, trágicas dessa realidade.

O câncer é umas das doenças que mais alteram a imagem corporal, imagem essa que o sujeito não deseja. 0 câncer de mama significa uma mutilação para as mulheres, visto que o seio é um dos principais representantes da feminilidade. Contudo, o surgimento do câncer de mama causa sequelas traumáticas para a mulher que vão além da doença em si. (ROCHA; ALMEIDA; RIBEIRO, 2013, p. 7)
Assim, como mais um exemplo de mulher empoderada, autônoma, resiliente, espiritualizada, ela se despede desse pedaço precioso do seu corpo feminino. 0 adeus à sua mama não retira a essência de ser ela mesma detentora de sua história, cujas raizes, fincadas na gênese de suas memórias autobiográficas, revelam-na para o mundo como Ana Eugênio, aquela que lutou contra o câncer, retirou sua mama e se reconstruiu outra vez como uma mulher para além de uma mama.

Agora vá, minha querida mama, pois sem você caminharei melhor ainda. Quanto ao prazer que me proporcionou, guardarei as doces lembranças e serei eternamente grata, pedaço de mim. Você não é uma pessoa, mas é parte de uma pessoa, pedaço de meu eu. Em breve, muito breve, serão somente cicatrizes. Siga bem, agora caminharei sem você, lutando por uma sociedade mais justa e denunciando os diversos tipos de violência e negação de direitos cometidos sobretudo contra menina/mulher, mulher/ menina. (SILVA, 2018, p. 58)

\section{O diálogo autobiográfico com}

\section{a espiritualidade: um caminho percorrido pela fé, promessa, devoção e cura na dança de São Gonçalo}

Realizar uma promessa para a cura de uma enfermidade não é algo tão simples, visto que passa por uma experiência individual e não tem necessariamente relação com religiões e crenças, contudo é na espiritualidade que o indivíduo pode se conectar com o que considera sagrado, com suas divindades, suas crenças, os diversos elementos em torno de suas promessas, o que irá remetê-lo ao plano da dimensão transcendental.

[...] Religião e espiritualidade foram consideradas como uma e a mesma coisa até a virada do século 19. A partir de então, estabeleceu-se gradualmente uma distinção entre elas. Religião 
passou a ser entendida como prática institucionalizada de um sistema de crenças, rituais e símbolos, compartilhada por uma comunidade. Espiritualidade, por sua vez, pode ser entendida como uma busca pessoal por significado e sentido maior no existir e sua relação com o sagrado e o transcendente, podendo estar vinculada ou não a uma religião formalizada ou designação religiosa. (DAL-FARRA; GEREMIA, 2010, p. 588)

A dimensão da espiritualidade de Ana Eugênio adentra em sua vida já desde a infância, quando participava e acompanhava seus familiares e a comunidade do Quilombo Sítio Veigå, em Quixadá, Ceará, na tradição religiosa da dança de São Gonçalo ${ }^{9}$, puxada pelo mestre Joaquim Roseno ${ }^{10}$. Essa tradição ocorria pelo repasse de conhecimento de seus ancestrais, sendo socializada oralmente de uma geração a outra, orientando sobre a importância da fé, da devoção e da promessa para a realização de um desejo, objetivo ou cura, sendo esses ensinamentos fundamentais para o fortalecimento de sua espiritualidade durante todo o seu processo de tratamento.

8 “[...] comunidade tradicional quilombola e rural localizada no distrito de Dom Maurício, também conhecido por Serra do Estevão, um dos pontos turísticos do município de Quixadá-CE. O Quilombo fica a $3 \mathrm{~km}$ da sede do distrito, $8 \mathrm{~km}$ do município Choró Limão e 25 km da cidade de Quixadá, no estado do Ceará" (SILVA, 2016, p. 19).

9 "A dança de São Gonçalo foi trazida pelo casal Chiquinho Ribeiro e Mãe Véia no início do século XX. O ritual é em homenagem ao santo português Gonçalo, que nasceu na cidade de Talgide, em 1187. Em Portugal, a tradicional festa é realizada na cidade de Amarante no dia 7 de junho, com uma semana de festejos, procissões, banda de música e folguedos populares. Gonçalo estudou em uma escola arquiepiscopal em Braga, foi ordenado sacerdote e posteriormente pároco de São Paio de Vizela. O culto ao santo foi permitido apenas no ano de 1551, pelo papa Júlio III, e foi canonizado em 1561" (SANTOS, 2009, p. 54).

10 “Essa expressão cultural é repassada através das gerações para os descendentes da comunidade. Atualmente, a dança é animada pelo neto de Chiquinho Ribeiro e Maria Ribeiro, seu Joaquim Ferreira da Silva (Joaquim Roseno), hoje com 79 anos, mestre da dança. Em 2010, foi reconhecido como Mestre da Cultura pela Secretaria da Cultura do Estado do Ceará, da qual passou a receber um salário vitalício e começou a participar do encontro dos mestres de cultura de todo o Brasil" (SILVA, 2016, p. 63).
Cabe destacar a importância da espiritualidade para a saúde. Na minha experiência, o território, o sentimento de pertencimento a uma cultura, a tradição religiosa da dança de São Gonçalo e o apoio da escrita contribuíram para o fortalecimento da minha espiritualidade, o contato com a dimensão transcendental dos ensinamentos dos meus ancestrais me orientando e energizando o meu ser interior rumo ao processo de cura. (SILVA, 2018, p. 16)

Assim, não tem como negar que São Gonçalo esteve presente durante todo o processo de tratamento na vida de Ana Eugênio. Inicialmente pedindo forças para superar o próprio diagnóstico positivo do câncer, depois nas sessões de quimioterapia e radioterapia, mas foi exatamente no momento de maior dor e aflição que recorreu ao santo. E isso ocorreu após sua primeira cirurgia de retirada da mama, precisando se submeter a uma segunda cirurgia de urgência com menos de 24 horas da primeira para a retirada de um coágulo e rompimento de um vaso sanguíneo. Diante de tanto medo, ela clamou por São Gonçalo, firmando devotadamente sua promessa.

Foi neste momento de dor e aflição que recorri a São Gonçalo e pedi forças para suportar a segunda cirurgia, em menos de vinte e quatro horas. Se porventura alcançasse a graça, em novembro do mesmo ano assistiria toda a dança e na última jornada ficaria em frente ao altar segurando São Gonçalo. (SILVA, 2018, p. 43)

Geralmente existe um ritual em torno das promessas ao santo, sendo estas pagas durante o mês de novembro, quando os pagadeiros das promessas seguem o percurso de uma procissão cantando e dançando em homenagem ao santo, o que simboliza ainda, para além da religiosidade e expressão cultural, uma forma de manter viva a tradição, a oralidade e a própria história acerca do Quilombo Veiga e seus ancestrais, o que demarca também seus territórios e identidades negras quilombolas, hoje realizada na Semana da Consciência Negra. 
A dança de São Gonçalo é comum em algumas comunidades quilombolas e consiste em uma tradição e marca identitária desse território negro. No entanto, [...] não é um espetáculo: fazem para celebrar e agradecer a boa colheita, o plantio. A dança, junto com a reza da folia, pagamento de promessas, preparação de comida, formam o conjunto amplo que compõe a festa em homenagem a São Gonçalo, religiosidade católica realizada na Semana da Consciência Negra no Quilombo Sítio Veiga. (VIDEIRA, 2009 apud SILVA, 2018, p. 59)

A dança é feita em 12 jornadas ${ }^{11}$, nome dado a cada repetição dos passos. As 11 primeiras jornadas são feitas em agradecimento ao bom ano na agricultura e à fartura. A última jornada é destinada ao pagamento de promessas alcançadas pelos moradores da comunidade ou de devotos de fora. As jornadas são contadas com sementes; 12 sementes começam nas mãos do contramestre e são passadas para o mestre ao fim de cada jornada. (SILVA, 2018, p. 57)

A consciência de si mesma também foi elemento fundamental que fortaleceu a espiritualidade de Ana Eugênio: ela nunca deixou de acreditar na superação de sua doença, colocando na fé em si mesma e nas suas devoções ao santo São Gonçalo total certeza de que iria vencer, que obteria sua cura. Ela deu em vários momentos exemplos de determinação, não se deixando influenciar por ninguém em suas decisões; mesmo sabendo dos riscos a que se submeteria em alguns procedimentos, ela nunca desistiu de si, não deixou de acreditar. Ela sonhou, ousou, estabeleceu metas e objetivos em sua vida, o que mostra que a espiritualidade envolve uma atitude de amor incondicional, respeito e crença em si acima de tudo.

A terceira promessa aconteceu quando meu organismo insistia em não aceitar a prótese, e minha mastologista falou que havia exposição da mesma e teria que retirá-la o quanto

11 "É a quantidade de vezes que eles cumprem e acertam a dança durante os versos em louvor" (SILVA, 2018, p. 57). antes para evitar infecção, lembrando que já era a segunda rejeição. Então, mesmo diante do risco, resolvi continuar; os motivos foram: sempre acredito que há sempre outra possibilidade além da que está posta; cada pessoa reage diferente a determinada ação; e mais ainda que iria tentar por mim, mas também por outras mulheres acometidas com o câncer e também pela equipe médica que fez todo o procedimento. Minha situação ficaria como experiência para todos, seja boa ou ruim. Parte de minha família e amigos dizia que eu estava louca: ir contra a palavra da médica, mas pensava cá comigo que nem todas as mulheres terão a coragem de enfrentar, então eu enfrentarei e sairei vitoriosa, tudo vai dar certo. Esta foi a frase mais repetida: 'vai dar certo'. A promessa ocorreu quando retornava para casa e até os dias atuais continuo com a mesma prótese. (SILVA, 2018, p. 62)

A força existente nas atitudes de Ana Eugênio fez com que ela trouxesse um significado para sua vida, ressignificando-a com olhar introspectivo para dentro de si, buscando alternativas para a superação de suas dores, refletindo sobre o mundo e as pessoas e estabelecendo uma conexão com sua espiritualidade. A partir dessa relação, traçou objetivos e metas de superação, não desistindo, compreendendo as questões inerentes à possibilidade de morrer, mas também de lutar pela vida com a devoção do seu santo protetor, São Gonçalo. Sendo esses elementos os mais importantes na dimensão espiritual, ou seja, lutar pela vida, como afirmam Sousa e Olinda (2015, p. 243):

A consciência da condição humana com todas as suas limitações e necessidades é fator impulsionador de busca do que há de melhor em nós mesmos e nos outros. Espiritualidade aparece como fortalecimento diante das diversas situações de dor, de aflição e de angústia. A espiritualidade é a âncora, é porto seguro que acalma, que tranquiliza e que orienta no sentido de acreditar e confiar em nós mesmos como sendo capazes de transgredir essas limitações e, assim, fortalecendo nosso interior diante dos desafios do dia a dia. 
Por fim, fica a relevância da dança de São Gonçalo, uma expressão cultural que foi capaz de se concectar com Ana Eugênio para além da dor e sofrimento, pois, com a graça alcançada, abriram-se os caminhos para fechar as cicatrizes que porventura ainda haviam ficado, descortinaram-se os caminhos para continuar vivendo e ampliou-se principalmente a força de continuar mais próxima da espiritualidade.

Os trechos adiante são da música de São Gonçalo, simbolizando a romaria e todas as trajetórias dos pagadores de promessa em torno da graça alcançada:

Eugênia quando se viu'

De dores amortecidas

Valeu-se de São Gonçalo

Logo foi favorecida.

São Gonçalo é um santo muito milagroso.

É de Deus amado, é de todo o povo.

Quem São Gonçalo serve, será servido.

É de Deus amado, é de todo o povo

Quem São Gonçalo serve, de coração.

É de Deus amado, é de todo o povo ${ }^{13}$.

Que nunca viu venha, venha ver (bis)

São Gonçalo no terreiro (bis)

Dançando com seus devotos (bis)

Junto com seus companheiros. (bis)

Ô que caminho tão longe

ô que areia tão quente

Se não fosse São Gonçalo

Aqui não tinha essa gente ${ }^{14}$.

Adeus, adeus, São Gonçalo

Até o ano que vem

Se a morte não nos matar

Se Deus quiser eu também ${ }^{15}$.

12 Trechos da música de São Gonçalo cantado por Ana Eugênio como forma de agradecimento à graça alcançada na promessa ao santo.

13 Esse verso é cantado quando se inicia a dança, em forma de batuque.

14 Esse verso é cantado já quase ao final da dança. Nesse momento todos os grupos saem do local onde está ocorrendo o ritual e dançam em torno desse espaço, dando uma volta completa.

15 Essa estrofe é uma das últimas cantadas e dançadas. É um momento muito místico, em que cada dançadei-
Graças a Deus já chegamos

Nesta casa de alegria

Onde mora santo Deus,

Filho da virgem Maria ${ }^{16}$.

\section{Considerações}

A autobiografia não é só um método importante para descrever e narrar a história de um sujeito social a partir dele mesmo, mas torna originais e fiéis esses escritos quando coloca em cena o próprio autobiografado como protagonista autônomo do seu próprio enredo, da reminiscência de sua memória.

Esse método abre ainda os caminhos para contestar a cientificidade positivista que tanto discriminou os registros históricos das populações tradicionais, sua oralidade e escritos, estabelecendo um modelo rígido, neutro na produção do conhecimento, um modelo de representatividade eurocêntrica, cuja hegemonia na produção do conhecimento negava sua validação, daí a importância de colocar os sujeitos sociais das populações étnicas como protagonistas de sua própria história, deixá-los transpor para o mundo a essência de suas memórias, que durante tanto tempo foram narradas sob o olhar ocidental eurocêntrico, de uma ciência positivista que silenciou e aprisionou não só seus corpos, mas suas vozes, seu potencial criativo.

Observamos, assim, que os escritos narrados foram mais do que uma autobiografia, por chamar a atenção para as particularidades e singularidades das comunidades de remanescentes quilombolas, ampliando o debate sobre o câncer a partir de um recorte étnico-racial, especialmente no que tange aos corpos negros femininos, ainda invisibilizados e fragmentados quando comparados às intervenções e às

ra - como chamamos as integrantes do grupo - vai ao pé do altar onde está São Gonçalo para agradecer por mais um ano de vida e também para pedir que esteja viva no ano seguinte.

16 Essa estrofe é cantada quando chega da pequena romaria. 
ações de saúde dirigidas às mulheres brancas do espaço urbano, sendo as quilombolas os maiores alvos de preconceitos, exclusão social e ação pontual.

Diante disso, faz-se relevante a luta dos profissionais do SUS e da sociedade civil organizada, especialmente das famílias, no campo, na defesa do sistema de saúde equitativo, justo, democrático, igualitário e, acima de tudo, humanizado, com atendimento integral, com instrumentos capazes de traçar o recorte étnico-racial, para que se reflita sobre a realidade dessas mulheres e se busquem meios para superar o estado de vulnerabilidade social em que se encontram quando acometidas pelo câncer.

A dimensão da espiritualidade também deixa uma porta aberta para que os profissionais da área de saúde atentem para a relevância desse aspecto para alguns pacientes; mesmo que seja desconhecida por muitos profissionais, a dimensão da espiritualidade traz elementos muito positivos no processo de enfrentamento de algumas enfermidades, possibilitando o alívio de alguns sofrimentos do paciente ou até mesmo, mediante sua fé, a cura de sua doença. Nem sempre os profissionais estão preparados ou treinados para lidarem com essa questão, fragilizando, muitas vezes, as possibilidades de intervenções para além da medicina convencional e dos fármacos.

Nesse sentido, valendo-se de São Gonçalo, Ana Eugênio externou momentos de profunda espiritualidade e devoção, em uma narrativa capaz de significar sua vida, como uma forma que encontrou de se conectar com seus ancestrais, de aliviar suas dores mais profundas, como a retirada de sua mama, o que nos leva a refletir como os sentimentos espirituais podem agir positivamente no organismo da pessoa, diminunido o seu sofrimento e trazendo suportes emocionais favoráveis, tais como a resiliência e a determinação estritamente li- gadas com seus sonhos de se manter viva, de lutar e de acreditar na sua superação, fortalecendo não só a sua espiritualidade, mas curando o seu corpo, equilibrando a sua mente e resgatando a sua saúde.

\section{Referência}

ALMEIDA, Gildênia Moura de Araújo. Capitão Duarte: caminhos em terras cearenses com educação, imprensa e amor proibido. In: MACHADO, Charliton José dos Santos (Org.). Desafios da escrita biográfica: experiências de pesquisa. Fortaleza: UECE, 2018. p. 40-58.

BEAUVOIR, Simone. 0 segundo sexo. São Paulo: Difusão Europeia, 1967.

BRASIL. Políticas de promoção de equidade em Saúde. Brasília, DF: Ministério da Saúde, 2007.

BRASIL. Políticas de promoção de equidade em Saúde. Brasília, DF: Ministério da Saúde, 2013.

BRASIL. Portaria n. 874, de 16 de maio de 2013. Institui a Política Nacional para a Prevenção e Controle do Câncer na Rede de Atenção à Saúde das Pessoas com Doenças Crônicas no âmbito do Sistema Único de Saúde (SUS). Diário Oficial [da] República Federativa do Brasil, Poder Executivo, Brasília, DF, 17 maio 2013.

BUENO, Belmira Oliveira. O método autobiográfico e os estudos com histórias de vida de professores: a questão da subjetividade. Revista Educação e Pesquisa, São Paulo, v. 28, n. 1, p. 11-30, 2002. Disponivel em: http://www.scielo.br/scielo.php?pid=S1517-97022002000100002\&script=sci_abstrac t\&tlng=pt Acesado em: 15 jul. 2019.

CORREIO NAGÔ. Câncer de mama: 3 coisas sobre mulheres negras. Correio Nagô: informação do seu jeito, 201-. Disponivel em: <https://correionago. com.br/portal/cancer-de-mama-3-coisas-sobre -mulheres-negras/>. Acesso em: 14 ago. 2019.

CUNHA, Fernanda Ielpo. Mercado de trabalho informal e família: uma análise sobre a esfera pública e privada numa perspectiva das mulheres de baixa renda do Parque Araturi- Caucaia. 2000. Trabalho de 
Conclusão de Curso (Graduação em Serviço Social) - Programa de Graduação em Serviço Social, Universidade Estadual do Ceará, Fortaleza, 2000.

DAL-FARRA, Rossano André; GEREMIA, César. Educação em saúde e espiritualidade: proposições metodológicas. Revista Brasileira de Educação Médica, Brasília, DF, v. 34, n. 4, p. 587-597, 2010. Disponivel em: http://www.scielo.br/scielo.php?script=sci_arttext\&pid=S0100-55022010000400015 Acesado em: 15 jul. 2019.

DOMINGOS, Luís Tomás. Entre estigmas e traumas de violência de colonização e escravidão: afirmação de identidade afrodescendente. São Leopoldo: EST, 2017.

GOLDENBERG, Mirian. A arte de pesquisar: como fazer pesquisa qualitativa em Ciências Sociais. 8. ed. Rio de Janeiro: Record, 2004.

MACHADO, Moreira Natália. Compreendendo os principais desafios do adolescente com câncer atendido pelo Hospital Peter Pan. Fortaleza: [s.n.], 2015.

MEDEIROS, Keytyane, Câncer de mama não vê cor? Mulheres negras têm mais chances de desenvolver a doença. 2018. Disponivel em: <cancer.www.oncogui.org.br>. Acesso em: 1o mar. 2018.

MINAYO, Maria Cecília de Souza. 0 desafio do conhecimento: pesquisa qualitativa em saúde. 8. ed. São Paulo: Hucitec, 2004.

OLINDA, Ercília Maria Braga de; SOUSA, Elaine Freitas de. Pensando o conceito de espiritualidade a partir das narrativas dos professores de Ensino Religioso. In: MATOS, Kelma Socorro Lopes de (Org.). Cultura de paz, educação e espiritualidade. Fortaleza: UFC, 2015. p. 237-252.

PENSESUS. Reforma Sanitária. PensesuS, 201-. Disponivel em: <https://pensesus.fiocruz.br/reformasanitaria>. Acesso em: 14 ago. 2019.

ROCHA, Iana Miranda Gorito da; ALMEIDA, Paulo César Toledo de; RIBEIRO, Juliana Fernandes de Souza. Seios, anseios e perdas: o corpo feminino e o cân- cer de mama como alvo de investimentos subjetivos. Revista Mosaico, Vassouras, v. 4, n. 1, p. 5-10, 2013. Disponivel em: http://editora.universidadedevassouras.edu.br/index.php/RM/article/view/160 Acesado em: 15 jul. 2019.

SANTOS, Vanessa Sardinha dos. "Outubro Rosa". Brasil Escola. Disponivel em: <https://brasilescola.uol.com.br/datas-comemorativas/outubro-rosa. htm>. Acesso em: 14 ago. 2019.

SIGNIFICADO do nome. Ana. Significado do Nome. 201-. Disponivel em: <https://www.significadodonome.com/ana/>. Acesso em: 14 ago. 2019.

SILVA, Ana Maria Eugênio. Enfrentamento e superação do câncer de mama: narrativa autobiográfica de uma mulher negra quilombola. 2018. 56f. Trabalho de Conclusão de Curso - (Graduação em Serviço Social) - Programa de Graduação em Serviço Social, Universidade Estadual do Ceará, Fortaleza, 2018.

SILVA, Cristiane Sousa da. Do Quilombo Sítio Veiga à universidade: uma experência extensionista antirracista no sertão central cearense. 2018. 196f. Tese (Doutorado em Educação Brasileira) - Programa de Pós-Graduação em Educação Brasileira, Universidade Federal do Ceará, Fortaleza, 2018.

SOUZA, Elizeu Clementino de. (Auto)biografia, histórias de vida e práticas de formação. In: NASCIMENTO; Antônio Dias; HETKOWSKI, Tânia Maria (Org.). Memória e formação de professores. Salvador: UFBA, 2007. p. 137-156.

VIEIRA, Ana Beatriz Duarte; MONTEIRO, Pedro Sadi. Comunidade quilombola: análise do problema persistente do acesso à saúde, sob o enfoque da Bioética de Intervenção. Saúde em Debate, Rio de Janeiro, v. 37, n. 99, p. 610-618, 2013. Disponivel em: http://www.scielo.br/scielo.php?pi$d=$ S0103-11042013000400008\&script=sci_abstrac t\&tlng=pt Acesado em: 15 jul. 2019.

Recebido em: 18.08.2019 Aprovado em: 03.03.2020 
Fernanda Ielpo da Cunha é Mestranda em Sociobiodiversidade e Tecnologias Sustantáveis pela Universidade da Integração Internacional da Lusofonia Afro-Brasileira - UNILAB. Possui Graduação em Serviço Social pela Universidade Estadual do Ceará - UECE. Especialização em Serviço Social, Políticas Públicas e Direitos Sociais pela Universidade Estadual do Ceará - UECE. Especialização em Gerontologia pela Faculdade Ateneu - FATE. E-mail: ferielpo@gmail.com

\section{Ana Maria Eugênio da Silva}

é Mestranda em Humanidades pela Universidade da Integração Internacional da Lusofonia Afro-brasileira - UNILAB. Graduada em serviço Social pela Universidade Estadual do Ceará e Graduanda em Antropologia pela UNILAB. Integra o movimento Quilombola. E-mail: anaeugenio.v@gmail.com

José Gerardo Vasconcelos é Professor Titular de Filosofia da Educação da Faculdade de Educação, da Universidade Federal do Ceará. Mestre em Sociologia pela Universidade Federal do Ceará, Doutor em Sociologia pela Universidade Federal do Ceará, Pós-Doutorado em Artes Cênicas, pela Escola de Teatro, da Universidade Federal da Bahia, PósDoutorado em Educação pela Universidade Federal da Paraíba, Pós-Doutorado em História da Educação pelo Centro de Educação, da Universidade Federal do Rio Grande do Norte. Líder do Grupo de Pesquisa de História e Memória da Educação do CNPq - NHIME. E-mail: gerardovasconcelos1964@gmail.com 